\title{
Costs of finding an advanced adenoma in colorectal screening
}

\author{
Jerome B Simon MD FRCPC
}

\begin{abstract}
ARTICLE
McGrath JS, Ponich TP, Gregor JC. Screening for colorectal cancer: The cost to find an advanced adenoma. Am J Gastroenterol 2002;97:2902-7.
\end{abstract}

\begin{abstract}
ARTICLE SUMMARY
The authors used computerized decision analysis to estimate the costs of finding and removing an advanced colonic adenoma in patients referred because of a positive fecal occult blood test. An advanced adenoma was defined as a villous adenoma, a tubular adenoma $10 \mathrm{~mm}$ or more in size, or a lesion that harboured highgrade dysplasia or cancer. Four strategies were compared: flexible sigmoidoscopy, flexible sigmoidoscopy plus air contrast barium enema, virtual colonoscopy (CT colography) and colonoscopy. Colonoscopy with polypectomy was undertaken if any of the methods detected a polyp. Probabilities and test characteristics were determined from the literature, and costs were estimated from the provincial fee schedule (Ontario) and local hospital sources. With an assumed $17 \%$ probability of an advanced adenoma being present, sigmoidoscopy was the most cost effective strategy at $\$ 1930$ to find and clear an advanced lesion, but the procredure missed between one-third and almost one-half of the lesions, depending on the depth of insertion. At $\$ 2290$, colonoscopy was slightly more expensive than sigmoidoscopy and more cost effective than either sigmoidoscopy plus barium enema (\$2840) or virtual colonoscopy (\$3681), neither of which detected as many advanced adenomas. The authors concluded that colonoscopy is the preferred investigative strategy and that improved access to colonoscopy is an important goal for occult blood screening programs.
\end{abstract}

\section{COMMENTARY}

This Canadian contribution adds to the expanding literature on the cost effectiveness of colorectal screening. There is a growing consensus in favour of screening the general middle-aged population, as costs appear to be acceptable when compared with lifeyears saved from colorectal cancer (1). However, what remains uncertain is the optimal screening modality. The literature is rife with conflicting results depending on various assumptions of test sensitivities and specificities, polyp prevalence and dwell time, significance of diminutive adenomas, procedural costs, etc. It is therefore not surprising that recent systematic reviews of the literature have concluded that the optimal screening strategy cannot be determined from the currently available data $(1,2)$.
A common screening tool is annual fecal occult blood testing (FOBT) coupled with flexible sigmoidoscopy every five years $(3,4)$. Recent evidence indicates that advanced adenomas are present in approximately $5 \%$ of the average-risk middle-aged population (5). Because FOBT is insensitive to polyps and many of these high-risk lesions are beyond reach of the sigmoidoscope, colonoscopy seems to be a more logical screening tool. Whether this is feasible is another question, because there are formidable barriers to its widespread use (6). Virtual colonoscopy is an interesting but less effective modality to date (7), although recent technical advances may alter this conclusion (8).

The present study by McGrath et al has two unique aspects. First, the cost calculations revolved around detection of advanced adenomas, not just any adenomatous polyp. This is arguably a more logical goal of screening, because these lesions are at highest risk of becoming malignant; lesser polyps are much more prevalent but also much less important, so their detection is presumably a less cost effective way of ultimately reducing mortality. More data are needed to assess this premise, but the approach taken by McGrath et al certainly has merit. Second, their calculations were based on subjects who were already FOBT-positive. This is a logical group to study, because FOBT screening is now widely practiced despite its major weaknesses, at least in the United States, and subjects who have positive tests are more likely to harbour high-risk lesions. For example, the authors used a $17 \%$ estimate of advanced adenomas in their modelling, based on data from Rockey et al (9). Their conclusion that colonoscopy is the best strategy to detect advanced lesions in these patients is not surprising. Although sigmoidoscopy seemed marginally more cost effective, most gastroenterologists would agree with the authors that it is less desirable than colonoscopy because its limited reach misses at least one third of the high risk lesions.

Several weaknesses of the study detract from its value. As in all similar papers based on mathematical modelling rather than observational data, the calculations and conclusions depend on a series of assumptions and probabilities that may not be valid. Cost estimates were based primarily on the Ontario fee schedule and did not include a detailed description of extensive indirect expenses that contribute to 'true' costs. As a result, the actual cost of detecting an advanced lesion is almost certainly much higher than the authors' estimate of $\$ 2000$ to $\$ 3000$. Furthermore, there is ambiguity in the text and tables about merely finding an advanced adenoma versus both finding and clearing the lesion (ie, the additional costs of colonoscopy and polypectomy for lesions detected by other means). Although the authors carried out a sensitivity analysis without substantially 
changing their conclusions, their data cannot be broadly applied because of major cost differences elsewhere, particularly in the United States.

It is also important to re-emphasize that their estimates apply only to FOBT-positive screened subjects, a small fraction of the general population. Costs of finding an advanced adenoma in a previously unscreened population would be substantially higher because the a priori prevalence of advanced lesions would be severalfold lower (10). Even for the population studied by McGrath et al, direct and indirect costs of the FOBT program need to be added for a more realistic estimate of overall cost effectiveness.

Despite these and other caveats, McGrath and his colleagues have provided a useful addition to the literature on colorectal screening as well as a Canadian context for cost determinations. Let us hope that other Canadian workers will expand upon their contribution to this important subject.

\section{REFERENCES}

1. Pignone M, Saha S, Hoerger T, Mandelblatt J. Cost-effectiveness analyses of colorectal cancer screening: a systematic review for the U.S. Preventive Services Task Force. Ann Int Med 2002;137:96-104.

2. Inadomi JM. Update on the cost-effectiveness of screening for colorectal neoplasia. Curr Opin Gastroenterol 2003;19:44-50.

3. Pignone M, Rich M, Teutsch, Berg AO, Lohr KN. Screening for colorectal cancer in adults at average risk: A summary of the evidence for the U.S. Preventive Services Task Force. Ann Int Med 2002;137:132-41.

4. Winawer S, Fletcher R, Rex D, et al. Gastrointestinal Consortium Panel. Colorectal cancer screening and surveillance: Clinical guidelines and rationale - update based on new evidence. Gastroenterology 2003;124:544-60.

5. Imperiale TF, Wagner DR, Lin CY, Larkin GN, Rogge JD, Ransohoff DF. Risk of advanced proximal neoplasms in asymptomatic adults according to the distal colorectal findings. N Engl J Med 2000;343:169-74.

6. Simon JB. Screening colonoscopy: is it time? CMAJ 2000;163:1277-8.

7. Simon JB. Motion - Computerized tomographic colography is a better method for screening for polyps: Arguments against the motion. Can J Gastroenterol 2003;17:129-31.

8. Pickhardt PJ, Choi JR, Hwang I, et al. Computed tomographic virtual colonoscopy to screen for colorectal neoplasia in asymptomatic adults. N Engl J Med 2003;349:2191-200.

9. Rockey DC, Koch J, Cello JP, Sanders LL, McQuaid K. Relative frequency of gastrointestinal lesions and colonic lesions in patients with positive fecal occult-blood tests. N Engl J Med 1998;339:153-9.

10. Lieberman DA, Weiss DG. Veterans Affairs Cooperative Study Group 380. One-time screening for colorectal cancer with combined fecal occult-blood testing and examination of the distal colon. N Engl J Med 2001;345:555-60.

\section{The authors respond:}

We greatly appreciate the opportunity to respond to Dr Simon's commentary regarding our article "Screening for colorectal cancer: The cost to find an advanced adenoma", which was published in the November 2002 issue of the American Journal of Gastroenterology. No formal programs are in place in Canada for screening the general population; however, many primary care physicians carry out screening as part of the annual health examination. Moreover, Cancer Care Ontario has recommended that the province of Ontario implement population-based fecal occult blood testing (FOBT) to screen average-risk individuals over 50 years of age for colorectal cancer (1).

As commented on by Dr Simon, we took a unique approach to our cost analysis study. We decided to ascertain the cost to find an advanced lesion(s) in a patient who is FOBT-positive, which is the type of patient of interest to Cancer Care Ontario. He commented that this limits the ability to generalize our study to the general population, since "the prevalence of advanced adenomas in the general population is several fold lower". In recent prospective studies of colonoscopic screening for asymptomatic average-risk individuals, however, the prevalence of advanced adenomas was found to be higher than originally thought. In the Veterans Affairs medical study published by Lieberman et al (2), the prevalence of advanced adenomas in asymptomatic individuals was $10.7 \%$. In our study, we used an adenoma prevalence of $17 \%$, which is not a several-fold difference. Although these numbers are not equal and colonoscopy would be more costly in this population, the increase in cost associated with a $6.3 \%$ difference in prevalence would be modest.

As Dr Simon pointed out, sigmoidoscopy seemed marginally more cost effective, but misses at least one-third of the high-risk lesions. This has been well documented in two large prospective trials, in which one-half of the patients with advanced proximal neoplasms had no distal colonic neoplasms (2,3). Furthermore, most physicians would recommend a complete examination of the colon for FOBT-positive patients of the type we studied. Therefore, sigmoidoscopy, if it were chosen by a physician, would be supplemented by an air contrast barium enema. Our analysis clearly demonstrated that colonoscopy is more cost effective than this combination. We also considered the possibility of virtual colonoscopy in this situation, but colonoscopy was again more cost effective.

Our study included the cost to remove all polyps that were found. Dr Simon raised some concerns that this was ambiguous, but we considered all pertinent hospital costs from a third-party payer. For example, if a patient underwent an initial sigmoidoscopy that revealed a polyp, the cost of the sigmoidoscopy, subsequent colonoscopy, polypectomy, equipment, nursing time, secretarial costs, recovery room time and even the cost of hospitalization if a perforation occurred were included.

Certainly Dr Simon is correct that our results cannot be applied to the United States, because of the enormous difference in fees and costs between the two countries. However, our numbers are applicable to the rest of Canada. In many provinces, nursing salaries and the fees paid to physicians are less than in Ontario, and the capital costs would be similar. Colonoscopy would be an even more cost effective option in these provinces. Conversely, higher fees would reduce the cost effectiveness of colonoscopy.

Colorectal cancer is the third most prevalent cancer in Canada and the second most deadly. It will afflict thousands of Canadians this year. Studies have shown that early detection at an asymptomatic stage by screening can improve survival and is cost-effective. Let us hope that screening average-risk individuals will soon be implemented at a national level.

$$
\begin{array}{r}
\text { Jerry S McGrath MD FRCPC } \\
\text { James C Gregor MD FRCPC } \\
\text { Terry Ponich MD FRCPC } \\
\text { Division of Gastroenterology, Department of Medicine, } \\
\text { University of Western Ontario, London, Ontario }
\end{array}
$$

\section{REFERENCES}

1. Ontario Expert Panel on Colorectal Cancer Screening. Colorectal Cancer Screening: Final Report. Toronto: Cancer Care Ontario, April 1999. <http://www.cancercare.on.ca/about_351.htm> (Version current at February 18, 2004).

2. Lieberman DA, Weiss DG, Bond JH, Ahnen DJ, Garewal H, Chejfec G. Use of colonoscopy to screen asymptomatic adults for colorectal cancer. Veterans Affairs Cooperative Study Group 380. N Engl J Med 2000;343:162-8.

3. Imperiale TF, Wagner DR, Lin CY, Larkin GN, Rogge JD, Ransohoff DF. Risk of advanced proximal neoplasms in asymptomatic adults according to the distal colorectal findings. N Engl J Med 2000;343:169-74. 


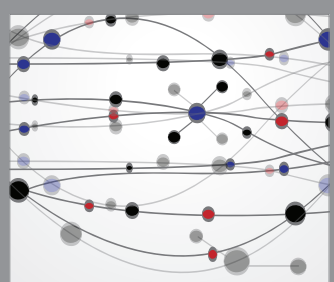

The Scientific World Journal
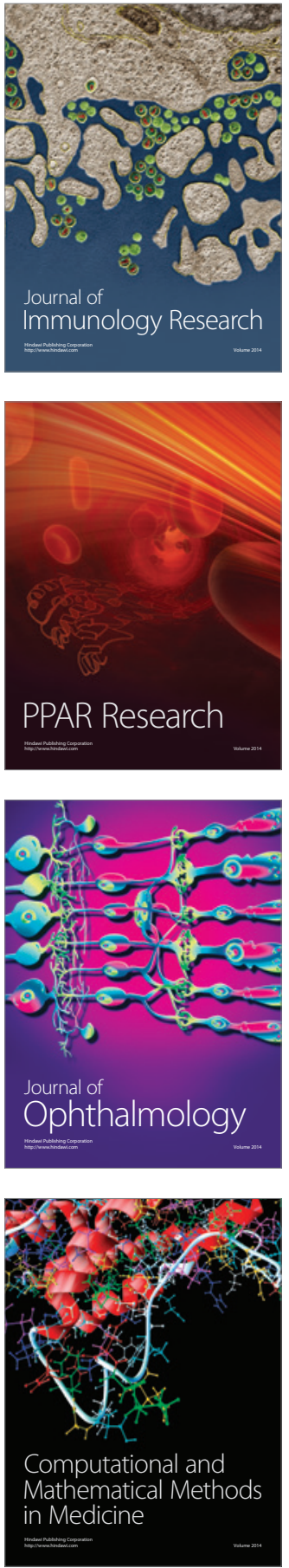

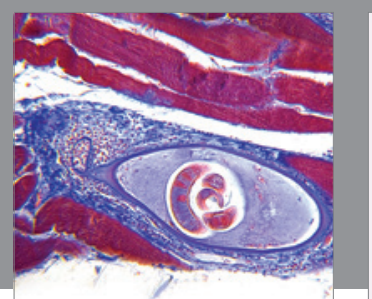

Gastroenterology Research and Practice

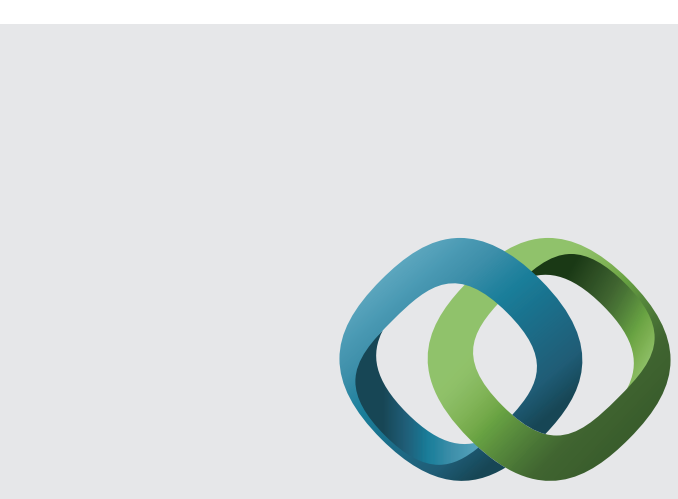

\section{Hindawi}

Submit your manuscripts at

http://www.hindawi.com
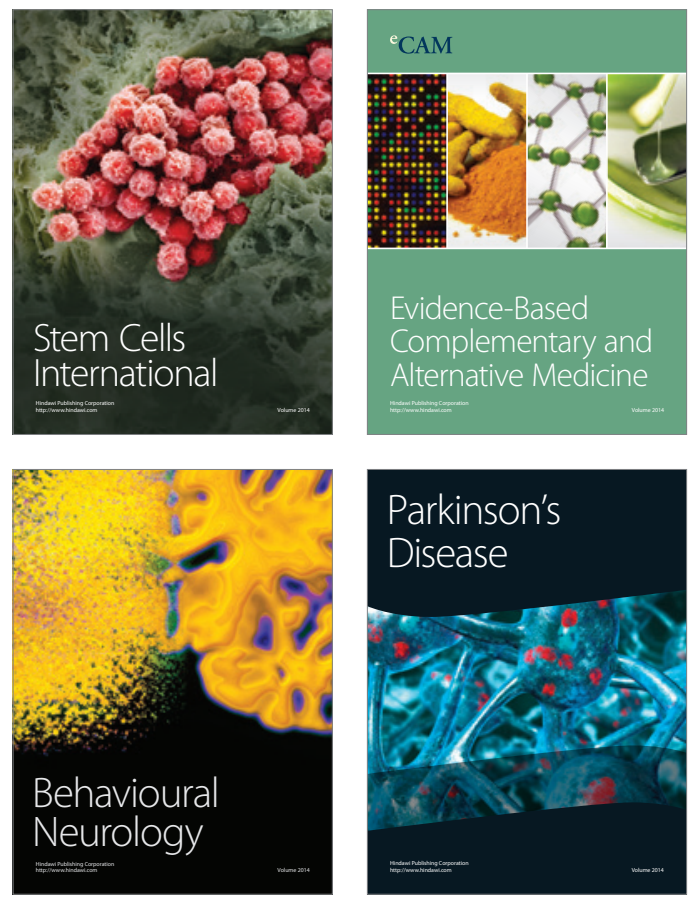
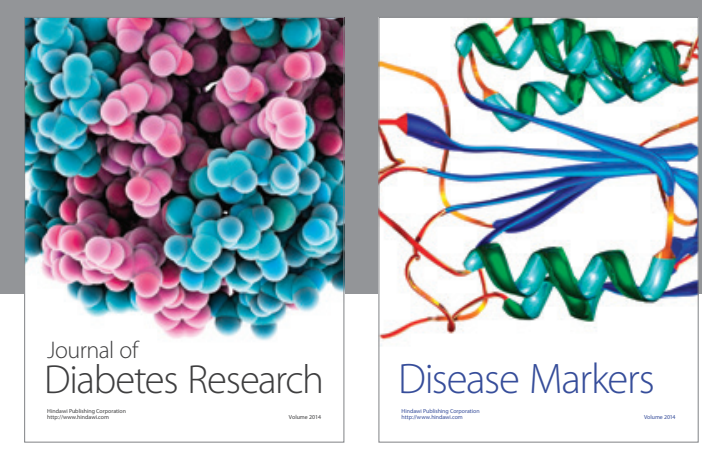

Disease Markers
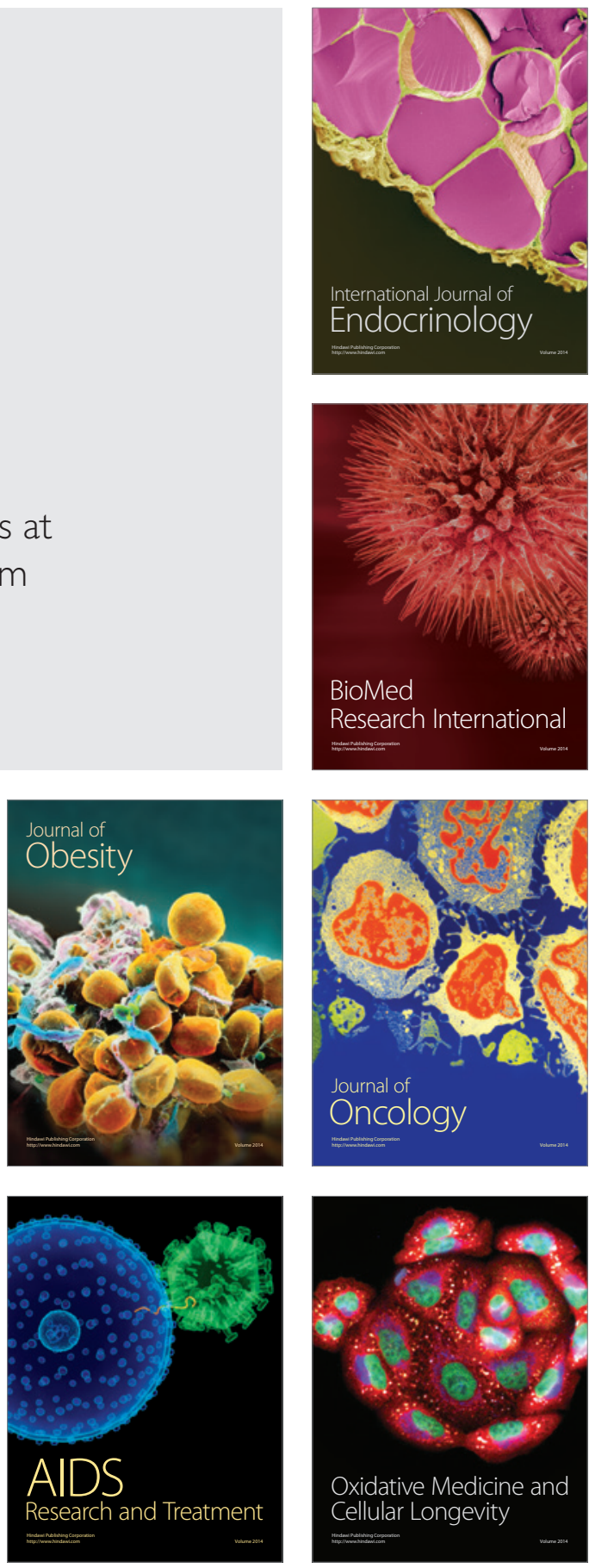